\title{
Method for Determining Critical Slip Surface of Cohesive Soil Slope Based on the Principle of Simple Penetration Test
}

\author{
Aiqing Zhang $(\mathbb{D}$, Jinyun Li, and Youheng Zhang \\ College of Architectural Engineering, North China Institute of Aerospace Engineering, Langfang 065000, China \\ Correspondence should be addressed to Aiqing Zhang; zhang000020@163.com
}

Received 7 July 2021; Revised 1 September 2021; Accepted 13 September 2021; Published 21 September 2021

Academic Editor: Fujiao Tang

Copyright $(2021$ Aiqing Zhang et al. This is an open access article distributed under the Creative Commons Attribution License, which permits unrestricted use, distribution, and reproduction in any medium, provided the original work is properly cited.

In order to propose a new method for determining the critical slip surface of the cohesive soil slope, the relational expression between the number of simple penetration and slope bearing capacity is established on the basis of studying the principle of the simple penetration test with reference to the research result concerning the number of standard penetration and bearing capacity of foundation soil. The measuring points are arranged at the slope of a certain road slope according to the actual conditions, to measure the number of simple penetration, calculate the slope bearing capacity at different depths with the relational expression, draw the curve of slope bearing capacity changing with the depth, search the points of abrupt change in slope bearing capacity to get the arc curve of abrupt change points, and then determine the critical slip surface of slope. The test results are compared with the results calculated by the finite element method (FEM) and theoretical method, to verify the feasibility and rationality of the simple penetration method. The research results show that the simple penetration method is applicable to and capable of quick and accurate determination of critical slip surface of the cohesive soil slope, thus providing a new method for analyzing the slope stability of cohesive soil.

\section{Introduction}

To determine the critical slip surface of slope is one of the key problems in the study of slope stability [1-3]. Experts and scholars both in and abroad made a lot of highly effective study to determine the critical slip surface of slope. Cheng et al. [4] and Sultan et al. [5], respectively, studied the determination of critical slip surface of slope from a theoretical point of view. Li et al. [6] proposed a method of simulating the slip surface with friction-contact interface unit. Jie et al. [7] and Yang and Deng [8] proposed a method of evaluating the slope safety with maximum acceleration. Zhang and Yang [9] proposed a new local strength reduction method. The analysis results with this method well coincide with the actual engineering conditions. Jiang [10] analyzed the deformation field and stress field of slope with FEM to determine the slip surface. Jiang [10] made full use of big data processing technology to establish the computing system for critical slip field of slope. In conclusion, experts and scholars both in and abroad mostly determine the critical slip surface of slope by regarding the safety coefficient as the evaluation indicator under the framework of finite element theory, which is unfavorable to field operation of road detection personnel.

Compared with the standard penetration method, the simple penetration method features simple operation and good applicability and is widely applied in engineering detection in recent years. Pan and Kitazono [11] analyzed the weakness of soil layer on disaster site with the simple penetration method. Guo [12] measured the melting depth of soil body in frozen earth area with the simple penetration method. Li et al. [13] took the simple penetration method as the new method to determine the compactness of clay subgrade with low liquid limit. As a result, the simple penetration method is taken as a new method to determine the critical slip surface of the cohesive soil slope in this paper. Besides, the feasibility and rationality of this method are verified through comparison with the finite element method and theoretical method in combination with engineering cases, hence of great research significance and wide application value. 


\section{Relationships between the Number of Simple Penetration and Bearing Capacity}

2.1. Simple Penetration Test. The simple penetration test is a kind of dynamic sounding, and the composition of the simple penetrometer is shown in Figure 1. It can be seen that the simple penetration test is to convert the potential energy of putting the piercing hammer at a certain height into the kinetic energy of penetrating into the soil body, so the principle of the simple penetration test is identical to that of the standard penetration test. Due to its simpleness, convenient operation, and applicability in various soil layers, this test equipment is widely used to judge the physicomechanical properties of soil body $[14,15]$.

The existing research results $[14,16]$ show that when the sounding probe penetrates into the soil layer for $10 \mathrm{~cm}$ deep, the blow count is recorded to judge the mechanical property of soil.

$$
\begin{aligned}
& \Delta h=h_{n}-h_{n-1}, \\
& N_{d}=\frac{N}{\Delta h} \times 10,
\end{aligned}
$$

where $\Delta h$ is the penetration depth of the sounding rod into the soil layer, $\mathrm{m} ; h_{n}$ is the tape reading at the $n$th hammering, $\mathrm{cm} ; h_{n-1}$ is the tape reading at the $n-1$ hammering, $\mathrm{cm} ; N$ is the number of hammering, times; and $N_{d}$ is the measured number of hammering, times.

\subsection{Relational Expression between the Number of Simple} Penetration and Bearing Capacity. The foundation bearing capacity can be evaluated by standard penetration times. When the soil is cohesive soil or silt, the relationship between the standard value of cohesive soil bearing capacity and the standard penetration blow number is selected as the relationship between the standard penetration times and foundation bearing capacity according to the specification requirements [17]. The relationship is as follows:

$$
f_{k}=19 N-74 \text {, }
$$

where $N$ is the standard penetration times, times, and $f_{k}$ is the foundation bearing capacity, $\mathrm{kPa}$.

It is known that the number of the simple penetration test is in twice relation to that of the standard penetration test [12]. With reference to the research results on the number of standard penetration and bearing capacity of foundation soil, the relational expression between the number of simple penetration and slope bearing capacity is established based on formula (2):

$$
f_{k j}=9.5 N_{j}-74 \text {, }
$$

where $N_{j}$ is the number of blow count, times, and $f_{k j}$ is the bearing capacity, $\mathrm{kPa}$.

\section{Engineering Application}

The cohesive soil slope at the left of section K560 +580 of Tongjiang-Sanya Expressway which is representative and subject to frequent slope instability in Heilongjiang Province

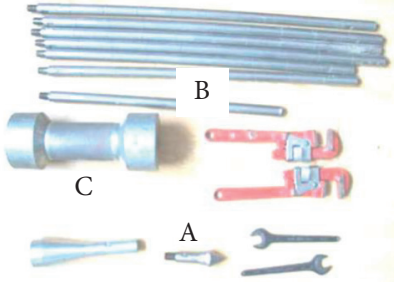

Figure 1: Composition of the simple penetrometer. A: penetrator, B: sounding rod, and C: piercing hammer.

is chosen as the research object. Its soil layer conditions and physical and mechanics parameters of soil body are given in Table 1. First, the detection point is determined, then the field test is carried out with the simple penetration method, the detection data are analyzed, and finally the critical slip surface of cohesive soil slope is determined.

3.1. Setting and Test of Measuring Points by the Simple Penetration Method. The cohesive soil slope at the left of section $\mathrm{K} 560+580$ is $6 \mathrm{~m}$ high, with the slope toe of $31^{\circ}$. The layout of detection points on-site is shown in Figure 2. It can be seen from Figure 2 that the spacing of other detection points is the same, viz., $2 \mathrm{~m}$, except the spacing between (1) and (2), (8), and (9), viz., $1 \mathrm{~m}$. The test is carried out in strict accordance with the steps required in Reference [16]. Three simple penetration tests are carried out at the same detection point, and the average can be taken if the difference among the results of three tests is within $5 \%$, and the tests are included into the number of the simple penetration test.

3.2. Test Results and Analysis. The test results are substituted into Formula (3) to calculate the slope bearing capacity, and the relation curve is drawn between slope bearing capacity and depth, as shown in Figure 3.

It can be seen from Figure 3 that slope bearing capacity shows continuous indentation change as the penetration depth increases. In the curves of \#1-6 detection points, there is always an inflection point where the slope bearing capacity is approximately equal to 0 . The points with slope bearing capacity approximately equal to 0 are defined as the abrupt change point of slope bearing capacity. There is no such abrupt change point in \#7-9 detection points, indicating that the critical slip surface of slope should pass through the slope sections of \#1-6 detection points rather than the slope sections of \#7-9 detection points.

Meanwhile, it is noted that the slope bearing capacity of \#7 and 8 detection points is lower than that of the other 7 points, indicating that the slope soil stability at the two detection sections is poor. It may cause downward slip with the slide mass of slope when the landslide condition is available.

The depth corresponding to the abrupt change points of slope bearing capacity is searched in (1)-(6) points in the curves shown in Figure 3, then marked on Figure 4, and the lines are connected, as shown in Figure 4. 
TABLE 1: Soil layer conditions and physical and mechanics parameters of soil body [12].

\begin{tabular}{lcccccc}
\hline Depth $(\mathrm{m})$ & Soil classification & Density $\left(\mathrm{g} / \mathrm{cm}^{3}\right)$ & Elastic modulus $(\mathrm{MPa})$ & Poisson's ratio & Cohesion $(\mathrm{kPa})$ & Internal friction angle $\left(^{\circ}\right)$ \\
\hline $0-0.8$ & Silty clay & 1.58 & 21 & 0.45 & 49.8 & 30.7 \\
$0.8-1.5$ & Loam & 1.654 & 28 & 0.38 & 95.8 & 28.7 \\
$1.5-2$ & Sand loam & 1.675 & 28 & 0.38 & 95.5 & 28.3 \\
$>2$ & Silty loam & 1.825 & 36 & 0.33 & 136.3 & 27.5 \\
\hline
\end{tabular}

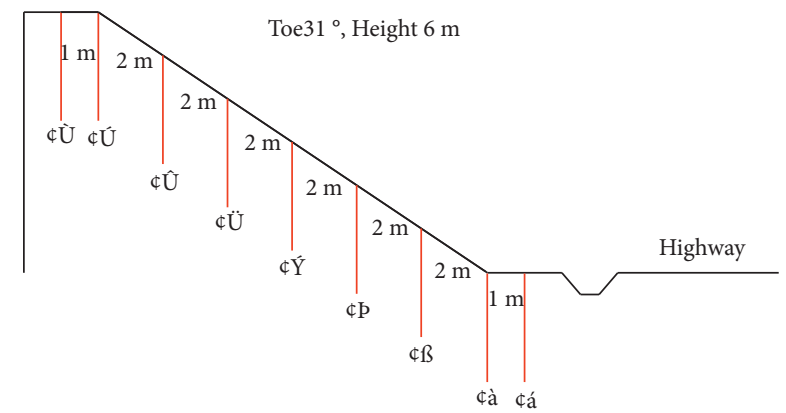

FIgURE 2: Detection points of cohesive soil slope (unit: $\mathrm{mm}$ ).

It can be seen from Figure 4 that the line connecting the abrupt change points of slope bearing capacity approximately equals to an arc curve, and this curve passes through \#1-6 detection points. The two ends of arc curve are connected to the slope boundary with CAD to get a complete arc curve, which is regarded as the critical slip surface of slope.

It can thus be seen that when the simple penetration test is used to search the critical slip surface of slope, if the points with slope bearing capacity of 0 appear and can be connected to form an arc, it indicates the possibility of landslide on the slope and measures should be taken to reinforce the slope.

Next, FEM and theoretical method will be used to verify the feasibility and rationality of the simple penetration test method.

\section{Comparison of Simple Penetration Method with FEM and Theoretical Method}

4.1. Comparison between Simple Penetration Method and FEM. The local strength reduction method identical with engineering practice is adopted for numerical calculation of engineering project $[18,19]$. The expression is as follows:

$$
\begin{aligned}
c^{\prime} & =\frac{c}{F}, \\
\phi^{\prime} & =\arctan \left(\frac{\tan \phi}{F}\right),
\end{aligned}
$$

where $c^{\prime}$ is the cohesion after reduction $(\mathrm{MPa}) ; \varphi^{\prime}$ is the internal friction angle after reduction $\left({ }^{\circ}\right)$; and $F$ is the reduction factor.

ABAQUS large finite element numerical simulation software is used for calculation and analysis following the calculation steps given in Reference [9] according to the geometric diagram of slope shown in Figure 5. Calculation is done according to the parameters given in Table 2 without consideration to the difference in the physico-mechanical properties of soil body of cohesive soil slope at varying depth.

When finite element strength reduction is used to analyze the slope issues, there will always be equivalent plastic strain concentration zone upon no convergence of calculation. That is to say, control slope failure unit can be obtained by controlling the maximum and minimum value of equivalent plastic strain in ABAQUS post-treatment document.

It can be obtained by numerical calculation that the safety coefficient (reduction factor) of the cohesive soil cut slope is 1.25 , and the scope of potential slip surface of slope is delineated by $\# 2$ red curve in Figure 6 .

The result obtained by the test method and that calculated by the local strength reduction method are compared, as shown in $\# 1$ and $\# 2$ curves in Figure 6.

It can be seen from Figure 6 that the critical slip surface of slope obtained by the simple penetration test is within the potential slip surface of slope calculated by the local strength reduction method. The slope bearing capacity of \#7 and \#8 detection points in the simple penetration test is lower than that of other detection points because these two points are within the potential slip surface of slope. The research shows that the result obtained by the simple penetration test is highly consistent with that obtained by FEM. It can thus be seen that the simple penetration method can determine the critical slip surface of slope, with certain feasibility.

4.2. Comparison between Simple Penetration Method and Theoretical Method. The comparison between the simple penetration method and the theoretical method shows that the critical sliding surface is used to represent the most likely sliding position when the slope is unstable. The sliding arc method is used for theoretical calculation of the model. Firstly, the center position of the sliding arc is determined by $4.5 \mathrm{H}$ method, and then the sliding arc is divided into strips to calculate the total sliding torque of the sliding surface and the total antisliding torque of the sliding surface. Finally, the safety factor of each sliding surface is calculated, and the sliding surface with the safety factor of 1.05 is the most dangerous sliding surface. The calculation results are shown in \#3 curve in Figure 6.

It can be known from Figure 6 that the critical slip surface of slope determined by the test method is basically consistent with the most dangerous slip surface of slope obtained by theoretical calculation, which indicates that the result obtained by the simple penetration method can be applied in engineering practice, hence proving the rationality of the simple penetration method in determining the critical slip surface of cohesive soil slope. 

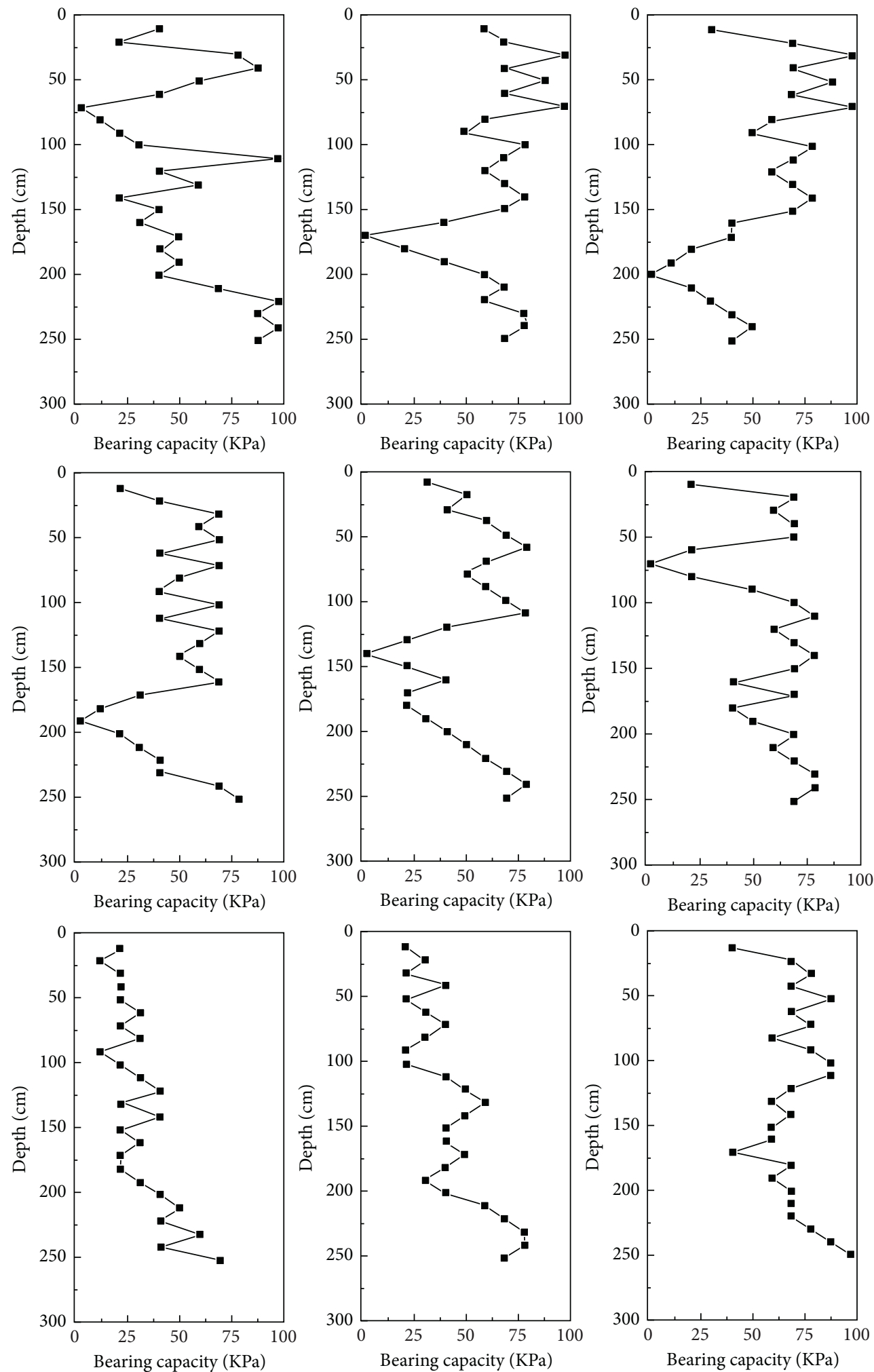

Figure 3: Results of the simple penetration test on the 9 detection points.

In conclusion, the simple penetration method is more authentic and representative compared with FEM. When compared with the traditional method of determining critical slip surface of slope represented by the standard penetration test, the simple penetration method features rapid and accurate determination in addition to numerous detection points. 


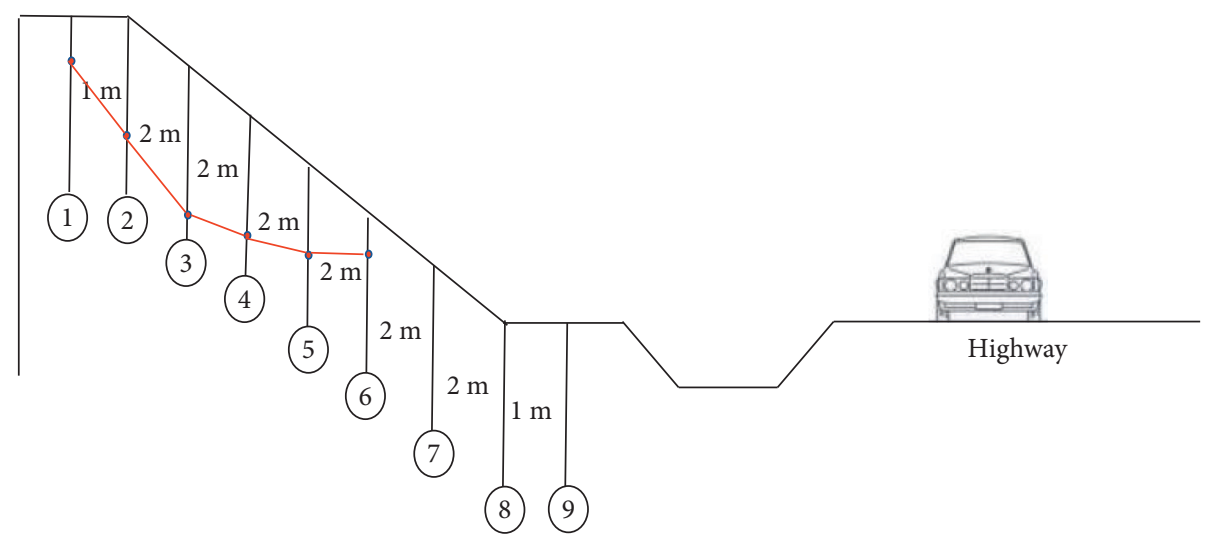

FIgURE 4: Arc curve of abrupt change points of slope bearing capacity (unit: $\mathrm{mm}$ ).

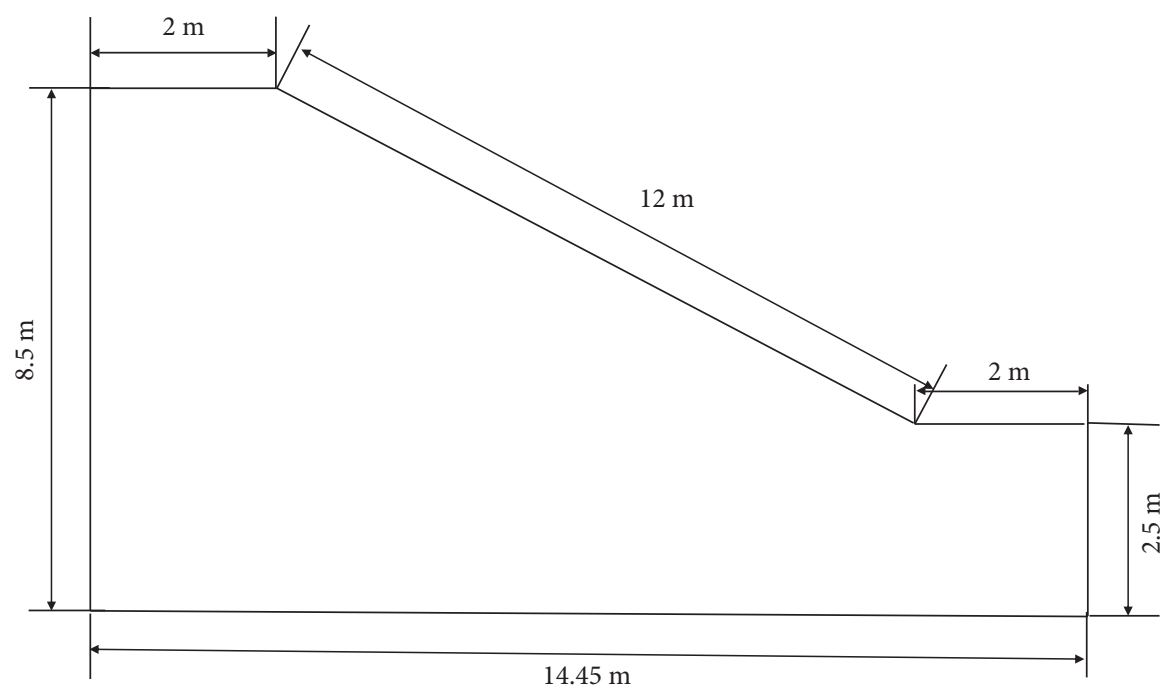

FIGURE 5: Geometric graph of slope.

TABLE 2: Parameters of cohesive soil of slope.

\begin{tabular}{lccccc}
\hline Parameter & Unit weight $\left(\mathrm{kN} / \mathrm{m}^{3}\right)$ & Elastic modulus $(\mathrm{MPa})$ & Poisson's ratio & Cohesion $(\mathrm{kPa})$ & Internal friction angle $\left({ }^{\circ}\right)$ \\
\hline Parameter value & 17 & 28 & 0.38 & 92.3 & $26.9^{\circ}$ \\
\hline
\end{tabular}

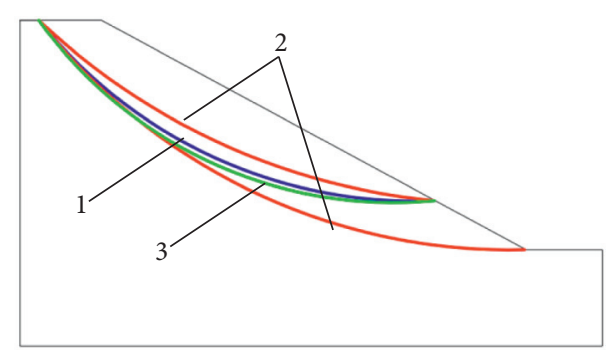

FIGURE 6: Comparison of the results obtained by the test method, FEM, and theoretical method (1 shows the critical slip surface of slope obtained by the simple penetration test, 2 shows the potential slip surface of slope calculated by FEM, and 3 shows the potential slip surface of slope obtained by theoretical calculation). 


\section{Discussion}

(1) Groundwater and precipitation are the main reasons for landslide. When the groundwater level rises or precipitation increases, the result of the test by the new method will decrease and the test result will be improved accordingly. So, the moisture content of soil layer during the test shall be measured when the simple penetration method is used in engineering practice, to guarantee accurate test result.

(2) In engineering practice, the slope height of $6 \mathrm{~m}$ is generally regarded as the basis of deciding whether to set cohesive soil slope. For single-stage cohesive soil slope ( $\leq 6 \mathrm{~m}$ high), the simple penetration method can be directly used to determine the critical slip surface of slope; for multistage cohesive soil slope (total height $>6 \mathrm{~m}$ ), the probe length can be corrected as required in the Specification for the Standard Penetration Test (YS/T 5213-2018), so it is recommended to adopt the simple penetration method and finite element strength reduction method to jointly analyze and comprehensively determine the critical slip surface of multistage cohesive soil slope.

(3) Whether for single-stage or multistage cohesive soil slope, the traditional method of determining the critical slip surface of slope is to propose the position of slip zone through analysis and judgment of technicians based on field investigation. However, the accuracy of traditional methods represented by the standard penetration method is not so high due to inconvenient operation and relatively few measuring points, so the finite element strength reduction method is mostly adopted at present. Compared with the finite element strength reduction method, esp. for seasonally frozen ground, miscellaneous soil, and some bad soil body, the simple penetration method can ensure more authentic and representative result while compared with the traditional method of determining critical slip surface of slope, it is faster and more accurate in addition to numerous detection points. To sum up, the simple penetration method has wide application value for determining the critical slip surface of soil slope.

\section{Conclusion}

(1) The principle of the simple penetration test is identical with that of the standard penetration test. With reference to relevant research results on the number of standard penetration and bearing capacity of foundation soil both at home and abroad, the relational expression between the number of simple penetration and slope bearing capacity is established.

(2) The simple penetration test indicates that the slope bearing capacity shows continuous zigzag change as the depth increases. Points with slope bearing capacity approximately equal to 0 are discovered within the range of penetration depth, and these points are defined as the abrupt change points of slope bearing capacity, which are connected to form the critical slip surface of slope.

(3) Both the simple penetration test method and FEM can obtain consistent results. Compared with theoretical calculation, the result obtained by the simple penetration method meets the requirements of engineering application, proving the feasibility and rationality of the simple penetration method in determining the critical slip surface of cohesive soil slope.

\section{Data Availability}

The experimental results used to support the findings of this study are included within the article.

\section{Conflicts of Interest}

The authors declare that they have no conflicts of interest.

\section{Acknowledgments}

The authors are grateful for the Doctoral Research Start-Up Fund Project of North China Institute of Aerospace Industry (BKY-2020-24).

\section{References}

[1] C. Sun, H. Zheng, C.-G. Li, and G.-H. Sun, "Critical slip surface search by using rigorous maximum residual thrust method based on ant colony algorithm," Rock and Soil Mechanics, vol. 35, no. 10, pp. 3021-3026, 2014.

[2] C. Sun, C.-G. Li, and H. Zheng, "Searching critical slip surfaces of slope based on global stability analysis," Rock and Soil Mechanics, vol. 34, no. 9, pp. 2583-2588, 2013.

[3] K. Zhang, A Study on Determination of Critical Slip Surface of Slope, Wuhan University, Wuhan, China, 2017.

[4] Y. M. Cheng, H. T. Liu, W. B. Wei, and S. K. Au, "Location of critical three-dimensional non-spherical failure surface by NURBS functions and ellipsoid with applications to highway slopes," Computers and Geotechnics, vol. 32, no. 6, pp. 387-399, 2005.

[5] N. Sultan, M. Gaudin, S. Berne, M. Canals, R. Urgeles, and S. Lafuerza, "Analysis of slope failures in submarine canyon heads: an example from the gulf of lions," Journal of Geophysical Research Atmospheres, vol. 30, no. 112, pp. 547-564, 2007.

[6] N. Li, S.-F. Guo, and X.-C. Yao, "A simulating method of the potential sliding surface of slope," Chinese Journal of Rock Mechanics and Engineering, vol. 35, no. 12, pp. 2377-2387, 2016.

[7] Y.-X. Jie, Y.-L. Bo, and B. Zhang, "Study on critical slip surface of acceleration in slope stability analysis," Journal of Engineering-GeoLoRy, vol. 25, no. 5, pp. 1238-1244, 2017.

[8] J.-C. Yang and Q. Deng, "Analysis of multistage slope potential sliding surface based on local strength reduction method," Hlghway, vol. 61, no. 12, pp. 19-23, 2016.

[9] Y.-C. Zhang, G.-H. Yang, H.-Y. Hu, P. Liu, and Z.-H. Zhong, "Searching for critical slip surface in soil slopes based on calculated results by variable modulus elastoplastic strength 
reduction method," Chinese Journal of Geotechnical Engineering, vol. 35, no. s1, pp. 14-22, 2013.

[10] Z.-F. Jiang, Improvement of Critical Slip Field Method Of Slope And Development Of Its Computing System, Hefei University of Technology, Hefei, China, 2016.

[11] Z.-J. Pan and Y. Kitazono, "Application of the handy hammer dynamic penetration test and plasticity chart in the geological hazards research," Soil Engineering and Foundation, vol. 29, no. 1, pp. 120-123, 2015.

[12] Y. Guo, The Mechanism Of Cutting Slope Freeze-Thaw Instability And Its Protection By Vegetation In High-Latitude Frozen Regions, Northeast Forestry University, Haerbin, China, 2013.

[13] J.-Y. Li, A.-Q. Zhang, and W. Shan, "Method for determining the compactness of low liquid limit clay subgrade based on simple penetration test," Journal of Central South University, vol. 48, no. 10, pp. 2732-2737, 2017.

[14] J.-Y. Li, A.-Q. Zhang, and D.-G. Liu, "Application of dynamic compaction to settling the collapsible loess," Technology \& Economy in Areas of Communications, vol. 14, no. 6, pp. 73-75, 2012.

[15] A.-Q. Zhang, J.-Y. Li, and D.-G. Liu, "Discussion on dynamic compaction for treatment of III weight level collapsible loess," Journal of Chongqing University of Science and Technology (Natural Science Edition), vol. 15, no. 1, pp. 161-163, 2013.

[16] A.-Q. Zhang, Compaction Technology of Highway Roadbedwidening Project, University.School of Civil Engineering, Harbin, China, 2009.

[17] Ministry of Construction of the People's Republic of China, Technical Specification for Construction Slope Engineering GB50331-2002, China Construction Industry Press, Beijing, China, 2002.

[18] A. Johari and A. R. Kalantari, "System reliability analysis of soldier-piled excavation in unsaturated soil by combining random finite element and sequential compounding methods," Bulletin of Engineering Geology and the Environment, vol. 80, no. 11, pp. 2485-2507, 2021.

[19] D. P. Deng and L. Li, "Limit equilibrium analysis of slope stability with coupling nonlinear strength criterion and double-strength reduction technique," International Journal of Geomechanics, vol. 19, no. 6, Article ID 104019052, 2019. 